\title{
PENGARUH PULMONARY REHABILITATION PROGRAM TERHADAP PENINGKATAN KUALITAS HIDUP PASIEN PENYAKIT PARU OBSTRUKSI KRONIK DI INSTALASI RAWAT INAP ROYAL PRIMA MEDAN
}

\section{The Influence of Pulmonary Rehabilitation Program Towards Improving the Quality of Life of Chronic Obstruction of Lung Diseases in Inpatient Installations Royal Prima Hospital Medan}

\author{
Constan Zamili ${ }^{1}$, Arieli Wau ${ }^{2}$, Epi Laia ${ }^{3}$, Ferdinandus Zagoto ${ }^{4}$, Tiarnida Nababan ${ }^{5}$ \\ ${ }_{1,2,3,4}$ Mahasiswa S1 Keperawatan, FKK Universitas Prima Indonesia Medan \\ Email: constanzamili969@gmail.com, arieliwau29@gmail.com, laiaepi65@gmail.com, \\ ferdinzagoto@gmail.com \\ ${ }^{5}$ Dosen Tetap FKK Universitas Prima Indonesia Medan \\ Email: tiarnidan@yahoo.com
}

\begin{abstract}
Abstrak
DOI : https://doi.org/10.34008/jurhesti.v4i1.95

Penyakit Paru Obstruksi Kronik (PPOK) merupakan masalah kesehatan yang saat ini ada di seluruh dunia. Penyakit paru obstruksi kronik membutuhkan perhatian khusus, pada pasien penyakit paru obstruksi kronik mengalami keterbatasan aktifitas, gangguan fisik dan psikologis sehingga hal ini akan mempengaruhi kualitas hidupnya. Salah satu upaya yang dapat dilakukan untuk meningkatkan kualitas hidupnya adalah pemberian Pulmonary Rehabilitation Program. Penelitian ini bertujuan untuk mengetahui pengaruh Pulmonary Rehabilitation Program terhadap peningkatan kualitas hidup pasien penyakit paru obstruksi kronik di Instalasi Rawat Inap Rumah Sakit Royal Prima Medan. Penelitian ini adalah penelitian pre ekperimental. Besar sampel adalah 10 orang. Sampel diambil menggunakan teknik accidental sampling yaitu pengambilan sampel secara aksidental (accidental). Instrumen yang digunakan adalah lembar kuisioner Pulmonary Rehabilitation Program dan lembar kuisioner kualitas hidup. Uji yang digunakan dalam penelitian ini menggunakan uji Wilcoxon. Hasil uji statistik dalam penelitian ini didapatkan $p$ value 0,014 maka dapat disimpulkan terdapat pengaruh yang signifikan antara pulmonary rehabilitation program terhadap peningkatan kualitas hidup pasien penyakit paru obstruksi kronik. Saran penelitian ini diharapkan bagi pihak rumah sakit khususnya perawat lebih meningkatkan pulmonary rehabilitation program khususnya pada pasien penyakit paru obstruksi kronik agar kualitas hidupnya meningkat.
\end{abstract}

Kata kunci : pulmonary rehabilitation program, PPOK, kualitas hidup

\begin{abstract}
Chronic obstruction pulmonary disease (COPD) is a health problem that currently exists worldwide. Pulmonary disease of chronic obstruction requires special attention, in patients of chronic obstruction of lung disease subjected to limited activity, physical and psychological disorders so that it will affect the quality of his life. One of the efforts that can be done to improve the quality of his life is the granting of Pulmonary Rehabilitation Program. The study aims to determine the influence of Pulmonary Rehabilitation Program on improving the quality of life of chronic obstruction lung disease in hospital inpatient installations of Royal Prima Medan. This research is pre-ecperimental research. The large sample is 10 people. Samples taken using accidental sampling technique are aksidental sampling (accidental). The instruments used are the Pulmonary Rehabilitation Program and the questionnaire sheet of life quality. The test used in the study uses the Wilcoxon test. The results of the statistical test in the study obtained $p$ value 0.014 can be concluded there is a significant influence between the pulmonary rehabilitation of the program on improving the quality of life of chronic obstruction pulmonary disease patients. The advice of this research is expected for the hospital especially the nurse further increase the pulmonary rehabilitation of the program especially in patients with chronic obstruction of lung disease to improve the quality of life.
\end{abstract}

Keywords : pulmonary rehabilitation program, COPD, quality of life

\section{PENDAHULUAN}

Penyakit Paru Obstruktif Kronik (PPOK) merupakan masalah kesehatan yang saat ini ada di seluruh dunia. Prevalensi, morbiditas, dan mortalitas
PPOK mulai meningkat sehingga mulai membutuhkan perhatian khusus dalam penatalaksanaan dan pencegahan terhadap penurunan progresivitas fungsi paru (Nungtjik, dkk, 2010). 
Berdasarkan hasil World Health Organization penyakit PPOK menjadi salah satu masalah tertinggi penyebab meningkatnya angka mortalitas di dunia. Angka kejadian PPOK pada tahun 2020 diperkirakan akan terus meningkat menjadi urutan ketiga di dunia. Penderita PPOK jarang ditemukan pada usia di bawah 40 Tahun (American Thoracic Society [ATS], 2011 dalam Oktorina, dkk, 2011).

Di Indonesia angka kejadian PPOK berada pada urutan kedua setelah penyakit asma. Provinsi dengan angka kejadian tertinggi terdapat di Nusa Tenggara Timur $(10,0 \%)$, disusul oleh Sulawesi Tengah $(8,0 \%)$, Sulawesi Barat $(6,7 \%)$, Sulawesi Selatan $(6,7 \%)$, dan Jawa Timur $(3,6 \%)$, sedangkan Provinsi Sumatera Utara $(3,6 \%)$ (Riset Kesehatan Dasar, 2013).

Beberapa hasil penelitian telah membuktikan manfaat dari Pulmonary Rehabilitation Program yang mampu meningkatkan kemampuan fisik tubuh penderita PPOK yang berdampak pada peningkatan kualitas hidup (Basuki \& Setiawan, 2014).

Setiap individu mempunyai kualitas hidup yang berbeda, hal ini di tandai dengan kemampuan seseorang dalam memanajemen masalah yang terjadi dalam kehidupan sehari-harinya. Semakin baik seseorang memanajemen dirinya, maka semakin baik pula kualitas hidupnya. Begitu pula sebaliknya jika seseorang tidak mampu memanajemen dirinya maka semakin buruk kualitas hidupnya (Khomsan, 2010).

Berdasarkan fenomena diatas maka peneliti tertarik untuk melakukan penelitian tentang pengaruh pulmonary rehabilitiation program terhadap peningkatan kualitas hidup pasien penyakit paru obstruksi kronik.

\section{METODE PENELITIAN}

Penelitian ini merupakan penelitian pre ekperimen dengan desain pre test- post test design yang bertujuan untuk mengetahui pengaruh pulmonary rehabilitation program terhadap peningkatan kualitas hidup pasien PPOK. Penelitian ini dilakukan di Instalasi Rawat Inap Royal Prima Medan. Subjek dalam penelitian ini adalah semua pasien didiagnosa dokter menderita penyakit paru obstruksi kronik yang sedang dirawat inap. Penelitian ini dilaksanakan pada tanggal 8 Juli -15 Juli 2019. Pengumpulan data dalam penelitian ini adalah data primer dengan cara meminta persetujuan terlebih dahulu kepada responden dan setelah itu peneliti membagikan kuesioner kepada responden dengan menjelaskan cara pengisian kuesioner. Selanjutnya, data yang sudah dikumpulkan dianalisis menggunakan analisis univariat dan analisis bivariat. Analisis bivariat menggunakan uji statistic Wilcoxon dengan program komputer SPSS.

\section{HASIL DAN PEMBAHASAN}

Tabel 1. Karakteristik Responden Berdasarkan Jenis Kelamin, Umur Dan Pendidikan Pasien PPOK Di Instalasi Rawat Inap Royal Prima Medan Tahun 2019.

\begin{tabular}{|c|c|c|}
\hline $\begin{array}{l}\text { Karakteristi } \\
\text { k }\end{array}$ & $\begin{array}{c}\text { Frekuen } \\
\text { si (n) }\end{array}$ & $\begin{array}{c}\text { Persentase } \\
(\%)\end{array}$ \\
\hline \multicolumn{3}{|l|}{ Jenis } \\
\hline \multicolumn{3}{|l|}{ Kelamin } \\
\hline a. Laki-laki & 9 & 90 \\
\hline $\begin{array}{l}\text { b. Perempua } \\
n\end{array}$ & 1 & 10 \\
\hline Total & 10 & 100 \\
\hline \multicolumn{3}{|l|}{ Umur } \\
\hline a. $40-59$ & 6 & 60 \\
\hline b. $60-69$ & 3 & 30 \\
\hline c. $70-79$ & 1 & 10 \\
\hline Total & 10 & 100 \\
\hline \multicolumn{3}{|l|}{ Pendidikan } \\
\hline a. SD & 1 & 10 \\
\hline b. SMP & 1 & 10 \\
\hline c. SMA & 7 & 70 \\
\hline d. D3 & 1 & 10 \\
\hline Total & 10 & 100 \\
\hline
\end{tabular}


Berdasarkan tabel 1 di atas dapat dilihat bahwa dari 10 responden menunjukkan bahwa, karakteristik responden berdasarkan jenis kelamin mayoritas responden jenis kelamin laki-laki sebanyak 9 responden $(90 \%)$ dan perempuan sebanyak 1 responden (10\%). Karakteristik responden berdasarkan umur mayoritas responden berumur 40-59 sebanyak 6 responden $(60 \%)$, minoritas dengan umur 70-79 tahun sebanyak 1 responden (10\%) dan umur 60-69 sebanyak 3 responden $(30 \%)$.

Berdasarkan karakteristik responden yang berpendidikan, mayoritas responden berpendidikan SMA sebanyak 7 responden $(70 \%)$, dan minoritas responden berpendidikan SD 1 responden (10\%), SMP sebanyak 1 responden(10\%) dan SMA sebanyak 1 responden (10\%).

Tabel 2. Distribusi Frekuensi dan Persentase Sebelum Dilakukan Pemberian Pulmonary Rehabilitation Program Terhadap Kualitas Hidup Pasien PPOK Di Instalasi Rawat Inap Prima Medan Tahun 2019 (Pre-Test).

\begin{tabular}{lcc}
\hline \multicolumn{1}{c}{ Variabel } & $\begin{array}{c}\text { Frekuensi } \\
(\mathbf{n})\end{array}$ & $\begin{array}{c}\text { Persentase } \\
(\%)\end{array}$ \\
\hline $\begin{array}{l}\text { Kualitas } \\
\text { Hidup }\end{array}$ & & \\
$\begin{array}{l}\text { Sebelum } \\
\text { a. Baik }\end{array}$ & 3 & 30 \\
$\begin{array}{l}\text { b. Kurang } \\
\text { baik }\end{array}$ & 7 & 70 \\
\hline \multicolumn{1}{c}{ Total } & $\mathbf{1 0}$ & $\mathbf{1 0 0}$ \\
\hline
\end{tabular}

Sumber : Data Primer 2019

Berdasarkan tabel 2 di atas menunjukkan bahwa, sebelum dilakukan pulmonary rehabilitation program pada pasien PPOK di royal prima medan tahun 2019 responden dengan kualitas hidup kurang baik sebanyak 7 responden $(70 \%)$ dan responden dengan kualitas hidup baik sebanyak 3 responden (30\%). Hal ini menunjukkan bahwa pasien yang menderita penyakit Paru obstruksi kronik mayoritas memiliki kualitas hidup kurang baik dan minoritas memiliki kualitas hidup baik.
Tabel 3. Distribusi Frekuensi dan Persentase Sesudah Dilakukan Pemberian Pulmonary Rehabilitation Program Terhadap Kualitas Hidup Pasien PPOK Di Instalasi Rawat Inap Royal Prima Medan Tahun 2019 (PostTest).

\begin{tabular}{lcc}
\hline Variabel & $\begin{array}{c}\text { Frekuensi } \\
(\mathbf{n})\end{array}$ & $\begin{array}{c}\text { Persentase } \\
(\mathbf{\%})\end{array}$ \\
\hline $\begin{array}{l}\text { Kualitas } \\
\text { Hidup } \\
\text { Sesudah }\end{array}$ & & \\
$\begin{array}{l}\text { a. Baik } \\
\text { b. Kurang } \\
\text { baik }\end{array}$ & 9 & 90 \\
\hline \multicolumn{1}{c}{ Total } & 1 & 10 \\
\hline Sumber : Data Primer 2019 & $\mathbf{1 0 0}$
\end{tabular}

Berdasarkan tabel 3 di atas menunjukkan bahwa setelah dilakukan pulmonary rehabilitation program pada pasien penyakit paru obstuksi di instalasi rawat inap rumah sakit royal prima medan tahun 2019 responden dengan kualitas hidup kurang baik sebanyak 1 responden (10\%) sedangkan responden dengan kualitas hidup baik sebanyak 9 responden (90\%) responden.

Tabel 4 Pengaruh Pulmonary Rehabilitation Program Terhadap Peningkatan Kualitas Hidup Pasien PPOK Di Instalasi Rawat Inap Royal Prima Medan Tahun 2019.

\begin{tabular}{|c|c|c|c|c|c|c|c|c|}
\hline \multirow{3}{*}{ PRP } & \multicolumn{8}{|c|}{ Kualitas Hidup } \\
\hline & baik & & $\begin{array}{c}\text { Kurang } \\
\text { baik }\end{array}$ & & total & & $Z$ & $P$ value \\
\hline & $n$ & $\%$ & $n$ & $\%$ & & & & \\
\hline pre & 3 & 30 & 7 & 70 & 10 & 100 & 200 & 4 \\
\hline post & 9 & 90 & 1 & 10 & 10 & 100 & & \\
\hline
\end{tabular}

Sumber : Uji Statistik Wilcoxon

Berdasarkan tabel 4 di atas menunjukkan bahwa dari 10 responden yang diberikan pulmonary rehabilitation program dengan signifikasi 0,05 atau $5 \%$. Berdasarkan hasil perhitungan wilcoxon signed rank test, maka nilai $\mathrm{Z}=-2.499$ dengan $\mathrm{p}<0,05(\mathrm{p}=0,014)$, maka Ho ditolak dan $\mathrm{Ha}$ diterima. Hasil diatas dapat 
disimpulakan bahwa ada pengaruh pulmonary rehabilitation program terhadap peningkatan kualitas hidup pasien PPOK di instalasi rawat inap royal prima.

Berdasarkan hasil uji Wilcoxon pengaruh pulmonary rehabilitation program terhadap peningkatan kualitas hidup pasien PPOK di instalasi rawat inap rumah sakit royal prima medan tahun 2019 berdasarkan nilai signifikasi 0,05 diperoleh hasil $p<0,05 \quad(p=0,014)$ dapat disimpulkan nilai yang berarti Ho di tolak Ha diterima. Kesimpulannya ada pengaruh pulmonary rehabilitation program terhadap peningkatan kualitas hidup pasien penyakit paru obstruksi kronik di instalasi rawat inap rumah sakit royal prima medan tahun 2019.

Menurut Basuki \& Setiawan (2014) program rehabilitasi paru melibatkan pasien dan anggota keluarga yang mampu mendukung serta memberikan dukungan sehingga pasien mampu meningkatkan dan mempertahankan kemandiriannya secara baik dan maksimal.

Hasil penelitian ini sejalan dengan penelitian yang dilakukan oleh Affyarsyah dkk (2009) penilaian kualitas hidup dilakukan dengan menggunakan lembar kuisioner SGRQ dimana penilaian kualitas hidup meningkat apabila terdapat penurunan nilai SGRQ. Data yang di peroleh dari hasil penelitian ini terdapat penurunan rerata nilai SGRQ pada kelompok perlakuan selama 6 minggu. Hal ini berati terjadi peningkatan kualitas hidup pada kelompok perlakuan karena perubahan minimal yang bermakna adalah terjadi penurunan nilai SGQR 4\%. Berdasarkan hasil ini perlakuan selama 6 minggu merupakan titik optimal dalam mencapai perbaikan kualitas hidup pasien penyakit paru obstruksi kronik (PPOK) dan dapat mempertahankan apa yang sudah tercapai, sehingga mampu memperlambat terjadinya penurunan kualitas hidup.

Penelitian ini menunjukkan bahwa Pulmonary Rehabilitation Program atau program rehabilitasi paru tersebut mampu meningkatkan kualitas hidup pasien penyakit paru obstruktif kronik.

\section{KESIMPULAN DAN SARAN}

Kesimpulan dari penelititian ini yaitu ada pengaruh pulmonary rehabilitation program terhadap peningkatan kualitas hidup pasien penyakit paru obstruksi kronik di Instalasi Rawat Inap Royal Prima Medan Tahun 2019.

Saran dari penelitian ini diharapkan dapat memberikan konstribusi dalam pengembangan asuhan keperawatan baik di rumah sakit maupun instansi pendidikan sehingga dapat diaplikasikan pada pelayanan keperawatan khususnya pada pasien PPOK dengan menitik beratkan pada Pulmonary Rehabilitation Program dalam upaya meningkatkan kualitas hidup dan promosi kesehatan kepada pasien.

\section{DAFTAR PUSTAKA}

Abidin, A., Yunus, F., Wiyono, W. H., \& Ratnawati, A. 2009. Manfaat Rehabilitasi Paru Dalam Meningkatkan Atau Mempertahankan Kapasitas Fungsional dan Kualitas Hidup Pasien Penyakit Paru Obstruktif Kronik Di RSUP Persahabatan. $J$ Respirindo , 29 (2).

Basuki, N., \& Setiawan. 2014. Peningkatan Kemampuan Fungsional Penderita PPOM Melalui Program Rehabilitasi Paru Di Rumah Sakit dan Di Rumah. Jurnal Terpadu Ilmu Kesehatan, 3 (1), 57-63.

Khomsan, A. 2010. Peranan Pangan dan Gizi Untuk Kualitas Hidup. Jakarta: Gema Insani.

Lara, A. G., \& Hidajah, A. C. 2016. Hubungan Pendidikan. Kebiasaan Olahraga, Dan Pola Makan Dengan Kualitas Hidup Lansia Di Puskesmas Wonokromo Surabaya. Jurnal Promkes , 4 (1), 59-69.

Notoatmodjo, P. S. 2012. Metodologi Penelitian Kesehatan. Jakarta: Rineka Cipta.

Nugtjik, A. K., Mangunnegoro, H., \& Yunus, F. 2010. Efikasi Pemberian Kombinasi Inhalasi Salmeterol dan Flutikason Propionat Melalui Alat Diskus Pada Penyakit Paru Obstruktif Kronik. Maj Kedokt Indon, 60 (12). 
Oktorina, Y., Jemadi, \& Rasmaliah. 2013. Karakteristik Penderita Penyakit Paru Obstruksi Kronik Yang Dirawat Inap Di Rumah Sakit Marta Friska Medan Tahun 20102011. Jurnal usu ,2 (1).

Patriani, A. A., Paramastri, I., \& Priyanto, M. A. 2010. Pemberdayaan Keluarga Dalam Rehabilitasi Medik Paru Pada Penderita Penyakit Paru Obstruksi Kronik Di Balai Pengobatan Penyakit Paru-Paru Yogyakarta. Berita Kedokteran Masyarakat, 26 (2).

Rab, P. T. 2010. Ilmu Penyakit Paru. Jakarta: Trans Info Media.

Riset Kesehatan Dasar. 2013. Retrieved from http://www. depkes.go.id.
Ritianingsih, N., \& Nurhayati, F. 2017. Lama Sakit Berhubungan Dengan Kualitas Hidup Pasien Penyakit Paru Obstruksi Kronis (PPOK). Jurnal Kesehatan Bakti Tunas Husada , 17 (1).

Suryantoro, E., Isworo, A., \& Upoyo, A. S. 2017. Perbedaan Efektivitas Pursed Lips Breathing Dengan Six Minutes Walk Test Terhadap Forced Expiratory. JKP , 5 (2). 